\title{
Comparison of students' use and acceptance of emergency online learning due to COVID-19 in the USA, Mexico, Peru, and Turkey
}

\section{A. Patricia Aguilera-Hermida, et al. [full author details at the end of the article]}

Received: 7 December 2020 / Accepted: 15 February 2021 / Published online: 14 April 2021

(C) The Author(s), under exclusive licence to Springer Science+Business Media, LLC part of Springer Nature 2021

\begin{abstract}
Due to the COVID-19 pandemic, and pursuant to the governments' order of citizens remaining at home, several countries were required to transition from face-to-face instruction to an online model to provide higher education to their students. While factors affecting the use of online learning are diverse and have been studied by models of use and acceptance of technology, this cross-sectional study explores the factors unique to the current emergency situation that influence students' use and acceptance of emergency online learning. Moreover, it proposes a model to predict a student's cognitive engagement in Mexico, Peru, Turkey, and the USA. This is a quantitative study with an exploratory and descriptive scope and cross-sectional design. Data was collected from 1009 students from the four countries, who completed surveys anonymously. The factors analyzed were attitude, affect, and motivation, perceived behavioral control (ease of use, self-efficacy, and accessibility), and cognitive engagement. The data was analyzed using descriptive, correlation, and regression analysis. The predictive model shows that students' attitude toward online learning impacts their cognitive engagement in Mexico, Peru, and the USA. Furthermore, self-efficacy is a significant moderator for cognitive engagement in all four countries. The model also shows that each country has different determinants for cognitive engagement. Understanding the factors that affect the use of emergency online learning is essential for the success and/or achievement of its maximum benefits in situations like a global pandemic. Limitations of this study have been identified as use of convenience sampling, and an inability to explore factors related to instruction and system attributes. Professors who did not teach online learning lacked knowledge about online educational strategies and used the technological resources that were immediately available to them. Therefore, research that explores the use of instructional strategies and the use of technological systems during emergency online learning is necessary. This study includes suggestions to incorporate open educational resources that use microlearning and emphasizes the importance of student self-efficacy; because it was predictor of cognitive engagement in all four countries. Faculty and higher education institutions can and should develop strategies to increase students' sense of self-efficacy.
\end{abstract}

Keywords Technology acceptance model $\cdot$ COVID-19 $\cdot$ Cognitive engagement $\cdot$ Selfefficacy $\cdot$ Emergency online learning 


\section{Introduction}

The use of online learning has become crucial around the globe. In 2020, the COVID19 pandemic forced higher education institutions in many countries to transition to remote learning. Faculty and students quickly had to adopt remote teaching and learning methods without any other options (Affouneh et al. 2020; Aguilera-Hermida 2020; Ali 2020; Daniel 2020; Hodges et al. 2020). Professors and administrators delivered education with synchronous and/or asynchronous online classes, many without the resources or the planning that digital technologies demanded to deliver a comprehensive study plan. In many cases, traditional classroom strategies were simply "transferred" to the virtual environment (Crawford et al. 2020; Hodges et al. 2020).

After eleven months, the pandemic is not under control in many countries, including Peru, Mexico, and the United States of America (USA), with the risk of COVID-19 becoming endemic (Hall et al. 2020; Murphy 2020). This means it is highly likely that remote teaching and learning will continue in the following months or years. People's beliefs and perceptions of technology influence its usage significantly (Saadé and Bahli 2005; Guerrero 2019). Therefore, we need to understand how students viewed their transition to online learning, thus providing higher education institutions with resources to offer better-planned instruction methods during this pandemic and be prepared for future emergencies (e.g. natural disasters, pandemics).

Also, understanding factors that affected the use and acceptance of emergency online learning will help online learning instructors and developers integrate them into future hybrid or online programs. This study aims to analyze the factors that affect students' use and acceptance of emergency online learning due to the COVID-19 pandemic in four countries: Mexico, Peru, Turkey, and the USA.

A pandemic is a prevalent disease around the world. At the end of 2019 and the beginning of 2020, an extremely infectious virus, the Coronavirus Disease 2019 (COVID-19), emerged, causing a respiratory illness and, in severe cases, the death of thousands of people. Because COVID-19 is highly contagious, in less than seven months, all but three countries around the globe reported cases (WHO 2020). Countries took different measures to stop the spread of the virus, such as social distancing, lockdowns, and/or stay-at-home orders. People were required to work or study from home in order to reduce the contagion. In many countries, higher education institutions moved to online learning without any preparation (Figallo et al. 2020; Huang et al. 2020; Pedró 2020). This decision has affected each country differently.

Even though digital skills are key for university students, not all countries have the same level of technology available for their citizens. The internet and the web are universal, but there are cultural differences and socioeconomic conditions that affect the use and acceptance of online learning (Jung 2014). There are countries where the majority of people have a device and internet access, such as the Netherlands, Belgium, or Australia, while in other countries, connectivity varies and is less available in rural and remote areas, such as in the United Kingdom (Hall et al. 2020). Furthermore, in least-developed countries, such as those in Latin America or the South of Europe, citizens may have even less-favorable connectivity conditions. In Latin America, only $52 \%$ of the population has a device and access to reliable stable internet (Pedró 2020). Students may be able to manage a computer and/or digital devices, but many of them 
may not be familiar with online learning, especially those from countries with low accessibility to educational technological tools (Lloyd 2020).

The use of technology in educational settings vary in each country. It is not only related to the history of distance education and online learning in the country, but also the type of university (private or public), the geographical location (rural or urban), the economic resources, and the government policies implemented (Affouneh et al. 2020; Huang et al. 2020; Lloyd 2020; Ramírez and Rodríguez 2020). In this study, we compared four countries: Mexico, Peru, Turkey, and the United States of America (USA).

Mexico has a long history of distance education (radio, mail, or teleconferences). After the development of the internet, distance education was transformed. The use of technology in the classroom increased, and universities such as ITESM or UNAM started using e-learning beginning in the 90s (Bosco and Barrón 2008). However, not many universities developed online programs, and the majority of higher education institutions offered most of their programs with a face-to-face teaching method (Ramírez and Rodríguez 2020).

In Peru, the majority of universities (70\%) did not have previous experience with virtual courses (Figallo et al. 2020). Some universities were using e-platforms and some digital resources, but not all of them. After the onset of the pandemic, private universities were leading the transition to online learning, but by May, many other universities started offering online courses (Cueva and Terrones 2020; Figallo et al. 2020).

Turkey's universities taught the majority of classes in-person, and some universities did not use e-learning at all. During the pandemic, Turkey's Council of Higher education guided all universities to establish distance education programs. The transition led to a new and unfamiliar learning environment for many students and professors (Gürler et al. 2020).

The USA had more experience with the use of technology in the classroom; since the 70s, some universities started using computers and emails to offer online courses (Harasim 2000). By 2003, many universities offered online programs. By 2015, most universities offered online resources that vary depending on the level of technology used in the course. There were in-person courses with less than $30 \%$ of technology (use of e-platforms and online resources), blended or hybrid courses with more than $30 \%$ of technology, and web courses that used more than $80 \%$ of technology or were completely asynchronous (Allen and Seaman 2015).

Despite their vast differences in culture, these countries are facing a common circumstance: the sudden transition to online learning due to a global pandemic. No matter their previous experience with the use of technology in the classroom, universities in the four countries had to implement emergency online learning. The four universities delivered in-person classes before the pandemic and transitioned to online learning due to COVID-19.

\subsection{Online learning}

Online learning is education delivered through the web and uses online tools for learning (Bower 2019; Gonzalez et al. 2020). It has been an excellent alternative for many people who cannot attend in-person classes around the world. Online learning has been used in different settings (industry, museums, etc.) and in recent years, in 
higher education (Harasim 2000; Panigrahi et al. 2018). Participants need a device such as a computer, a tablet, or a cell phone, as well as internet access. Classes are held synchronously, which means professors and students meet virtually at a specific time, asynchronously, allowing students to complete assignments at another time and place that fits their schedule, or in a blended/hybrid format where most of the content is delivered online (Allen and Seaman 2015; Hall et al. 2020).

When designed properly, online education can increase access to higher education for populations who otherwise would be excluded, and can have effective learning processes where students reach the expected learning goals (Bozkurt and Sharma 2020; Hodges et al. 2020). During the pandemic, higher education institutions started offering classes in different and new modalities (e,g., some students remotely and some students in the classroom in real-time). Each institution must respond to its particular circumstances and needs (Affouneh et al. 2020; Huang et al. 2020). This new teaching method is called "emergency online learning" (Hodges et al. 2020).

Online education requires students to have more self-discipline than in the face-toface method (Jung 2014). Moreover, in online learning, instructors have to work harder than in traditional classroom education to maintain learning engagement, which is considered imperative for learning outcomes (Panigrahi et al. 2018). Also, online learning offers specific online pedagogical practices and materials designed to engage the learner in a unique online learning culture that increases students' success (Bower 2019; Jung 2014).

The potential for having an effective online higher education depends more on the practices and the initiatives of the faculty and institutions than on the technology (Bower 2019; Jung and Lee 2020; Wang et al. 2013). Currently, some innovative tools exist to enhance students' engagement in online spaces. These tools can be found and accessed as open educational resources (OERs).

OERs are educational resources that reside in the public domain that facilitates their free use, adaptation, and distribution (Hilton 2020; UNESCO 2020; Tang 2020). OERs can be open textbooks, lecture notes, presentations, multimedia audio, animations, illustrations, assignments and/or quizzes. Hilton (2020) found that students were less likely to drop courses when utilizing OERs instead of textbooks and showed greater satisfaction with the learning experience. Moreover, students reported that OERs are as good or better than commercial textbooks.

Many effective OERs are designed based on microlearning. Microlearning refers to short lessons designed to offer specific content through a device. Course segments are divided into bite-sized lessons that can be accessed at any time by the student (Díaz Redondo et al. 2021; Jahnke et al. 2020). The segments may include a diversity of formats (games, videos, quizzes, and so forth) and offer instant feedback to the learner. Professors can use these short lessons during synchronous or asynchronous online learning and the learner can access to the information 24/7. Students value microlearning within the learning environment because they can easily complete short sessions and learn or reinforce specific bits of information (Birch and Lewis 2020).

OERs that use microlearning can be an excellent tool to support professors who do not have online teaching experience (Huang et al. 2020; Van Allen and Katz 2020). Some of them can be incorporated into Learning Management Systems and be auto-graded. Professors who cannot design online materials (due to lack of experience or knowledge) can integrate micro-units previously created and available in open repositories of online learning. 
Not only is this more affordable, but it is accessible to more students (Emrich et al. 2019; Hilton 2020). OERs are accessed through a computer and/or a mobile device (Van Allen and Katz 2020). In order to facilitate technology adoption among professors and students, it is critical to select friendly platforms and learning system managements that can be accessed or monitored from mobile devices (Jahnke et al. 2020; Kadada and Tshabalala 2020). Clearly, online education effectiveness depends on many factors, and the degree of acceptance is one of the most important aspects (Tarhini et al. 2017).

The factors affecting the use, adoption, and acceptance of technology have become a topic of great interest. Due to the increase in use, technology acceptance models have become a theoretical framework about the use and acceptance of online technologies (Jung 2014). The most used models are the TAM model (Davis 1989), the AIUTA-2 model (Venkatesh et al. 2012), and the GETAMEL model (Abdullah and Ward 2016). The factors that these models use are based on different theories related to motivation, PC utilization, cognitive theory, and adoption of information, amongst others (Guerrero 2019; Jung and Lee 2020; Kemp et al. 2019). Many researchers have used these models to analyze the use and acceptance of specific educational technologies such as open educational resources (Jung and Lee 2020), e-learning systems (Pham and Tran 2020; Yakubu and Dasuki 2019), multimedia technology (Park et al. 2019), and other technological educational tool home loans for homes.

However, many researchers have developed their own models based on the original models. They design their instruments by adapting the model to the specific technology that they are analyzing and, in many cases, they add new constructs to the models (Park et al. 2019; Pham and Tran 2020) or propose new models (Martinho et al. 2018). Furthermore, structural equation modeling depends on the variables that the researcher includes to analyze the variability. This has resulted in great variability in the constructs to measure the use and acceptance of technology. Kemp et al. (2019) considered that constructs and measurement models vary considerably, producing inconclusive outcomes. Based on this, they developed a flexible taxonomy with measurements specifically suited to educational technology.

\subsection{Kemp et al.'s taxonomy of factors that affect the use and acceptance of technology}

Kemp et al. (2019) reviewed the theories and definitions that formed the basis of the constructs of the TAM and the UTAUT models. Constructs sharing similar characteristics were collated into similar groups. After that, they confirmed the groups with Abdullah and Ward, creators of the GETAMEL model (2016), and incorporated constructs specifically relevant to educational technology.

Subsequently, Kemp et al. reviewed the factors used in 125 papers that cited "Technology Acceptance Model", "TAM", "UTAUT" or "GETAMEL", and then created a taxonomy with the aim of being "concise, inclusive, comprehensive and extendable" (2019, p. 2396). The description of the factors and their components were summarized from Kemp et al.'s analysis of "the constructs that comprise the foundational behavioral intention models" (2019, p. 2398). The taxonomy is focused on factors that affect attitudes towards the use of educational technologies by students and educators in higher education institutions. The final taxonomy's primary groups were: attitude, affect, and motivation; social factors; usefulness and visibility; 
instructional attributes; perceived behavioral control; cognitive engagement; and system attributes.

For this research, we did not choose all the factors. During emergency online learning, factors related to technology (usefulness and visibility and system attributes) or instruction were not planned and/or improvised. After the sudden transition to online learning, many professors did not know how to adapt the class content to an online setting, and they had to learn technology while they were using it. Universities and faculty members used the systems that were available, but there was not enough knowledge or time to analyze system functions or attributes. Moreover, social factors were highly affected by the COVID-19 pandemic. Students did not know how to interact during online classes nor did professors know how to promote social interactivity. Therefore, we did not include factors related to system attributes, social interaction, or instruction.

We considered only factors that relate to students' approach and experience such as attitude, affect, and motivation; perceived behavioral control; and cognitive engagement. Even though the taxonomy does not offer a detailed definition of the final factors, it includes the theories behind it. We reviewed the literature behind the constructs that we selected for this study and followed Kemp et al.'s taxonomy because it was clear and integrative.

The factors that served as a theoretical framework to investigate the use and acceptance of emergency online learning due to COVID-19 in this study are the following:

\subsubsection{Attitude, affect, and motivation}

Kemp et al. (2019) considered that the user's attitude, affect, and motivation are interrelated, so they grouped them.

- Attitude: Refers to the individual's positive or negative evaluation of a behavior.

- Affect: Measures the user's satisfaction or liking of the behavior. It also includes the users' emotional state.

- Motivation: Is defined by intrinsic motivation, where individuals performed an act by themselves, not for any external reward or results. It is focused on the learner's motivation to learn.

\subsubsection{Perceived behavioral control}

This refers to the user's capability and effort, and the environmental conditions. It includes:

Ease of use: The degree to which the user expects an effortless behavior. It is based on previous use of the technology. The actual use has an impact on how it will be used over a course of time.

Self-efficacy: User's judgment of their own capabilities required to complete designated tasks. It is not based on their actual skills, but on the belief of what a person considers capable of doing.

Accessibility: This includes how frequently a user can access e-learning systems, and the ability to use devices without time or place limitations. 


\subsubsection{Cognitive engagement}

This refers to the cognitive processes that allow users to absorb knowledge. It includes the focus, attention, and absorption of materials by the learner.

Even though we included a regression model, the analysis is not about predicting the future use of emergency online learning. Instead of behavioral intention, we focused on cognitive engagement. Learning engagement is considered a proxy for learning outcomes (Panigrahi et al. 2018; Pham and Tran 2020). Currently, there is not enough information about the impact of the transition to emergency online learning from the learning outcomes of the students per country. Therefore, we included a regression model using cognitive engagement as the dependent variable and compared how common factors used in previous research (such as attitude, affect, motivation, and perceived behavioral control) predict cognitive engagement among participants from the USA, Mexico, Peru, and Turkey. The following model was used (Fig. 1).

Many countries may need to continue with emergency online learning, so understanding students' experience will allow higher education institutions to continue using the strategies that work and to change those that are deficient. Furthermore, this understanding will help when considering possible implications for future online experiences (due to an emergency or not). Finally, the cross-cultural analysis will help higher education institutions to observe similarities and differences between the four countries.

The questions that guided this research were the following:

- What is the student's perception regarding attitude, affect, and motivation, behavioral control (self-efficacy, use of technology, and accessibility), and cognitive engagement, and how do these factors relate to each other in Mexico, Peru, Turkey, and the USA?

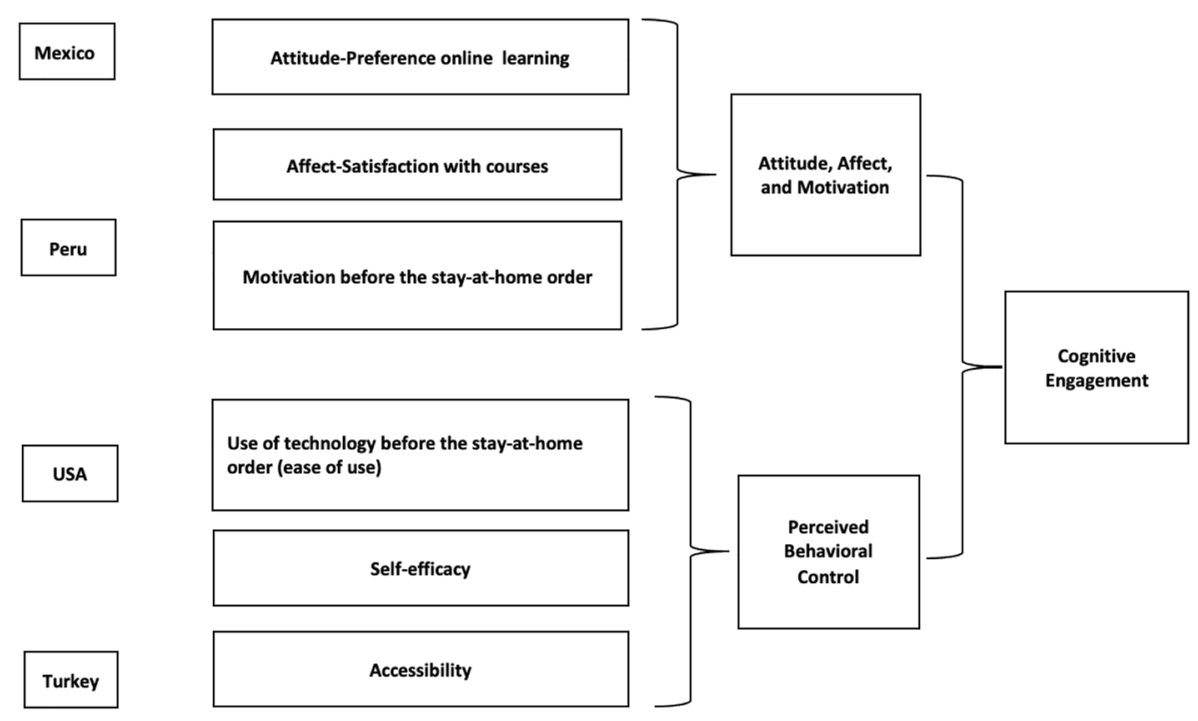

Fig. 1 Proposed research model 
- Do attitude, affect, and motivation, and behavioral control (self-efficacy, use of technology, and accessibility) predict cognitive engagement?

\section{Method}

This is a quantitative study with an exploratory and descriptive scope, and a crosssectional design. Many countries had to transition to online learning and researchers started to question in what ways the countries differ or were similar in terms of the acceptance of online learning due to COVID-19. The study was conducted in four universities from Mexico, Peru, Turkey, and the USA respectively. Sampling was based on convenience in terms of the presence of collaborators in universities and their access to participants during emergency online learning.

Researchers from each country obtained approval from their respective Institutional Review Boards. Participants answered an online questionnaire while they were still under stay-home orders and/or remote teaching and learning. The guest researchers translated the questionnaire and confirmed the cultural accuracy of the translation. After the data collection, the principal researcher compared de-identifiable information.

\subsection{Participants}

Participants were college students carrying out Behavioral Science and Health -Psychology, Nursing, Human Development and Family Studies - areas mainly from the authors' home institutions. The total convenience sample was $N=1009$, from Mexico (323), Peru (299), Turkey (125), and the USA (262). All the students signed an informed consent, participated voluntarily in the study, and received no remuneration. Most of the respondents were female (64\%) undergraduate students; (87\%) between 18 to 22 years old $(74 \%)$. The demographics per country are presented in Table 1.

\subsection{Procedure}

Data was collected using Qualtrics Software. We used an online questionnaire that the principal researcher implemented based on Kemp et al.'s (2019) taxonomy of factors that affect the use and acceptance of technology and the review of the constructs from previous models (Abdullah and Ward 2016; Davis 1989; Venkatesh et al. 2012). The questionnaire included demographic items and items focused on assessing motivation, affect, and attitude; perceived behavioral control; and cognitive engagement among college students. The items were adapted to assess the experience during emergency online learning due to COVID-19 and some items asked about the students' perception before and after the stay-at-home orders to have a more relevant assessment of their experience during this period. Questions are presented below in the context of analysis.

\subsection{Data analysis}

The data was analyzed in different steps. Before we started the analysis, we conducted a test of homogeneity of variances. Results showed a significance of less than .05 for the 
Table 1 Demographics per country

\begin{tabular}{|c|c|c|c|c|c|c|c|c|}
\hline & \multicolumn{8}{|c|}{ Countries } \\
\hline & \multicolumn{2}{|c|}{$\begin{array}{l}\text { Mexico } \\
n=323\end{array}$} & \multicolumn{2}{|c|}{$\begin{array}{l}\text { Peru } \\
n=299\end{array}$} & \multicolumn{2}{|c|}{$\begin{array}{l}\text { Turkey } \\
n=125\end{array}$} & \multicolumn{2}{|c|}{$\begin{array}{l}\text { United States } \\
n=262\end{array}$} \\
\hline \multicolumn{9}{|l|}{ Education Level } \\
\hline Undergraduate & 303 & $93.8 \%$ & 242 & $83.4 \%$ & 125 & $100 \%$ & 227 & $86.6 \%$ \\
\hline Graduate & 20 & $6.2 \%$ & 57 & $16.6 \%$ & & & 35 & $13.4 \%$ \\
\hline \multicolumn{9}{|l|}{ Courses } \\
\hline $1-2$ courses & 26 & $8.0 \%$ & 63 & $21.1 \%$ & 3 & $2.4 \%$ & 30 & $11.6 \%$ \\
\hline 3-4 courses & 33 & $10.2 \%$ & 99 & $33.1 \%$ & 6 & $4.8 \%$ & 54 & $20.8 \%$ \\
\hline 5 or more & 264 & $81.7 \%$ & 137 & $45.8 \%$ & 116 & $92.8 \%$ & 175 & $67.6 \%$ \\
\hline$F=63.42, p<.001$ & \multicolumn{2}{|c|}{$\begin{array}{l}M=5.29 \\
S D=1.37\end{array}$} & \multicolumn{2}{|c|}{$\begin{array}{l}M=4.04 \\
S D=1.65\end{array}$} & \multicolumn{2}{|c|}{$\begin{array}{l}M=5.76 \\
S D=0.87\end{array}$} & \multicolumn{2}{|c|}{$\begin{array}{l}M=4.57 \\
S D=1.36\end{array}$} \\
\hline \multicolumn{9}{|l|}{ Sex } \\
\hline Females & 282 & $87.3 \%$ & 195 & $65.2 \%$ & 108 & $86.4 \%$ & 167 & $63.7 \%$ \\
\hline Males & 40 & $12.4 \%$ & 103 & $34.4 \%$ & 17 & $13.6 \%$ & 95 & $36.3 \%$ \\
\hline Other & 1 & $0.3 \%$ & 1 & $0.3 \%$ & & & & \\
\hline \multicolumn{9}{|l|}{ Age } \\
\hline 18 to 22 & 257 & $79.6 \%$ & 175 & $58.5 \%$ & 114 & $91.2 \%$ & 194 & $74.6 \%$ \\
\hline 23 to 26 & 50 & $15.5 \%$ & 62 & $20.7 \%$ & 11 & $8.8 \%$ & 47 & $18.1 \%$ \\
\hline 27 to 45 & 14 & $4.3 \%$ & 40 & $13.4 \%$ & & & 19 & $7.3 \%$ \\
\hline 46 to 61 & 2 & $0.6 \%$ & 22 & $7.4 \%$ & & & & \\
\hline$F=32.11, p<.001$ & \multicolumn{2}{|c|}{$\begin{array}{l}M=21.5 \\
S D=4.08\end{array}$} & \multicolumn{2}{|c|}{$\begin{array}{l}M=25.26 \\
S D=9.06\end{array}$} & \multicolumn{2}{|c|}{$\begin{array}{l}M=20.55 \\
S D=1.23\end{array}$} & \multicolumn{2}{|c|}{$\begin{array}{l}M=21.75 \\
S D=3.65\end{array}$} \\
\hline
\end{tabular}

four countries. We analyzed the reliability of the instrument through Chronbach's Alpha tests, and the results showed constructs over .65 for the four countries. Descriptive analyses were used to identify and describe the sample in terms of the participants' characteristics (e.g., age, gender, etc.). Then, additional descriptive analyses were carried out to report the percentage responses for different categories that are provided for each item in the survey. Finally, correlational methods (Pearson product-moment, $t$ test, multiple linear regression) were used to identify differences among the participants based on their respective countries. The analysis presents the similarities and differences of the factors between countries and a predictive model for cognitive engagement.

\section{Results}

As Table 2 shows, in the comparison between countries, we found a statistically significant difference in all the factors. However, many factors have a very similar trend. This is crucial because it indicates that students from the four countries had similar perceptions and experiences during the transition to emergency online learning. First, we present the 
Table 2 Educational technology acceptance factors based on Kemp et al.'s (2019) taxonomy

\begin{tabular}{|c|c|c|c|c|c|c|c|c|c|}
\hline \multirow[t]{3}{*}{ Variables } & \multirow{3}{*}{$\begin{array}{l}\text { ANOVA }(F) / \text { Kruskal } \\
\text { Wallis }(H)\end{array}$} & \multicolumn{8}{|c|}{ Countries } \\
\hline & & \multicolumn{2}{|c|}{$\begin{array}{l}\text { USA, } \\
n=262\end{array}$} & \multicolumn{2}{|c|}{$\begin{array}{l}\text { Mexico } \\
n=323\end{array}$} & \multicolumn{2}{|c|}{$\begin{array}{l}\text { Peru } \\
n=299\end{array}$} & \multicolumn{2}{|c|}{$\begin{array}{l}\text { Turkey } \\
n=125\end{array}$} \\
\hline & & $M$ & $S D$ & $M$ & $S D$ & $M$ & $S D$ & $M$ & $S D$ \\
\hline $\begin{array}{l}\text { Attitude - Preferred face- } \\
\text { to-face }\end{array}$ & $H=38.62, p<.001$ & 4.49 & 0.89 & 4.59 & 0.79 & 4.20 & 1.04 & 4.62 & 0.87 \\
\hline $\begin{array}{l}\text { Attitude - Preferred online } \\
\text { learning }\end{array}$ & $H=71.59, p<.001$ & 1.98 & 1.23 & 1.91 & 1.14 & 2.57 & 1.27 & 1.72 & 1.13 \\
\hline Affect - Satisfied with courses & $H=38.06, p<.001$ & 3.32 & 1.25 & 3.38 & 1.22 & 3.15 & 1.27 & 2.56 & 1.30 \\
\hline Affect - Wellbeing & $F=32.48, p<.001$ & 2.51 & 0.94 & 3.18 & 1.11 & 2.52 & 1.00 & 2.37 & 1.13 \\
\hline Affect - Negative emotions & $F=7.137, p<.001$ & 3.84 & 0.93 & 3.62 & 1.11 & 3.96 & 1.00 & 4.00 & 1.07 \\
\hline $\begin{array}{l}\text { Motivation before } \\
\text { stay-at-home order }\end{array}$ & $F=9.328, p<.001$ & 3.19 & 0.62 & 3.28 & 0.51 & 3.08 & 0.55 & 3.02 & 0.62 \\
\hline $\begin{array}{l}\text { Motivation after stay-at-home } \\
\text { order }\end{array}$ & $F=84.05, p<.001$ & 2.27 & 0.81 & 3.10 & 0.73 & 2.43 & 0.69 & 3.10 & 0.70 \\
\hline Use of Technology - Before & $F=85.72, p<.001$ & 3.09 & 0.73 & 2.83 & 0.67 & 2.22 & 0.58 & 2.42 & 0.85 \\
\hline Use of Technology - After & $F=117.72, p<.001$ & 4.28 & 0.73 & 4.62 & 0.50 & 3.68 & 0.64 & 4.33 & 0.70 \\
\hline Self-efficacy & $F=24.89, p<.001$ & 2.63 & 0.87 & 3.22 & 0.94 & 3.11 & 0.90 & 3.34 & 0.86 \\
\hline Accessibility & $F=25.13, p<.001$ & 3.40 & 0.59 & 3.64 & 0.46 & 3.30 & 0.47 & 3.31 & 0.64 \\
\hline Cognitive engagement & $F=23.25, p<.001$ & 2.39 & 0.92 & 2.95 & 0.87 & 2.91 & 0.74 & 2.69 & 0.92 \\
\hline
\end{tabular}

results of the factors during the transition to emergency online learning due to COVID-19. Then, we present a model explaining how these factors may predict cognitive engagement during online learning among the USA, Mexico, Peru, and Turkey.

\subsection{Attitude, affect, and motivation}

For attitude, affect, and motivation, we asked specific questions to each sub-group.

\subsubsection{Attitude}

Attitude refers to the individual's positive or negative evaluation of the behavior (Kemp et al. 2019; Venkatesh et al. 2003). The students' preference for a teaching/learning delivery method implies a positive attitude towards the method. Therefore, we asked students about their preference towards face-to-face or remote teaching, and if they struggled with adapting to remote learning and teaching. In Mexico, Peru, Turkey, and the USA, participants showed a strong preference for the face-to-face learning method over online learning.

The more students preferred the face to face method, the more they struggled during the emergency online learning. The four countries showed a significant positive moderate correlation between preference for face-to-face and struggling with adapting to online learning: Mexico, $r_{s(323)}=.46, p<.001$; Peru, $r_{s(299)}=.45, p<.001$; Turkey, $r_{\mathrm{s}(125)}=.37, p<.001$; and the USA, $r_{s(249)}=.54, p<.001$. Also, in the four countries, 
there was a negative significant correlation between preference for online learning and struggle $\left(\right.$ Mexico, $r_{s(323)}=-.38, p<.001 ;$ Peru, $r_{s(299)}=-.50, p<.001$; Turkey, $r_{\mathrm{s}(125)}=$ $-.23, p<.05$; and USA $r_{s(249)}=-45, p<.001$,) indicating fewer students struggled in adapting to the emergency online learning.

Moreover, the preference of students towards face-to-face learning negatively impacted their cognitive engagement, especially in the USA $r_{S(234)}=-.39, p<.001$ and Peru $\mathrm{r}_{\mathrm{s}(299)}=-.39, p<.001$, where there was a significantly negative moderate relationship. Students from Mexico $r_{S(323)}=-.17$ and Turkey $r_{S(125)}=-.19$, showed a weak negative relationship at the $p<.05$ level. On the other hand, there was a positive significant relationship between students' preference for online learning and students' cognitive engagement. The USA, $\mathrm{r}_{\mathrm{s}(234)}=.38$, and Peru $r_{s(292)}=.47$ showed a moderate correlation, and Mexico $r_{s(323)}=.30$ a weak correlation, all at the $p<.001$ level. Turkey showed a weak correlation, $r_{s(125)}=.23$ at the $p<.05$ level. Responses from the four countries confirmed that students who preferred online learning had a better cognitive engagement and struggled less during the emergency online learning than students who preferred face-to-face (negative attitude towards online learning). Moreover, participants who preferred face-toface learning had more difficulties during the emergency online learning period and had a negative cognitive engagement in the four countries.

\subsubsection{Affect}

Affect refers to the user's satisfaction with the use of technology and the user's emotional state (Guerrero 2019; Saadé and Bahli 2005). We asked students if they were satisfied with their courses. There was a statistically significant difference between the four countries. Students from Mexico showed more satisfaction with courses, followed by the USA, Peru, and Turkey. Students from the four countries showed a positive correlation between satisfaction with their courses and cognitive engagement $\left(\right.$ Mexico, $r_{S(323)}=.35$, Peru $r_{s(299)}=.52$, Turkey $r_{\mathrm{s}(125)}=.50$, and USA $r_{s(235)}=.48$, all at the $p<.001$ level).

Regarding the students' emotional state, students were asked: "Describe how your emotional states have changed after the stay-at-home order related to COVID19", and we listed life satisfaction and happiness for wellbeing. The construct showed a good internal consistency (Cronbach's Alpha for the USA $\alpha=.84$, Mexico $\alpha=.88$, Peru $\alpha=.86$ and Turkey $\alpha=.86$ ). For negative emotions, we listed stress, anxiety, and apathy with good internal consistency in the four countries (Cronbach's Alpha for the USA $\alpha=.78$, Mexico $\alpha=.87$, Peru $\alpha=.88$, and Turkey $\alpha=.88)$.

Students' emotional states were compared between countries using a one-way ANOVA test that showed significant differences for wellbeing $(F=32.48, p<.001)$ and negative emotions $(F=7.137, p<.001)$. Post hoc comparison using Tukey HSD for wellbeing showed that only Mexican students' wellbeing was statistically higher than students' wellbeing in the other three countries. The USA, Turkey, and Peru students' responses did not vary significantly. For negative emotions, post hoc Tukey comparison showed that students from the four countries experienced an increase in their negative emotions during the stay-at-home order without significant difference between the USA, Mexico, Peru, and Turkey. 


\subsubsection{Motivation}

Motivation refers to the students' drive to learn (Maldonado et al. 2009; Jung and Lee 2020). For this factor, we asked about the students' reasons for pursuing school before and after the transition. The reasons listed were: talk to classmates, interact with professors, hang out, do academic activities, complete projects, interest in in-class topics, and finish degree studies. We calculated a mean score for the seven "before" and "after" items for each country. Using Cronbach's Alpha analysis, responses showed a good internal consistency for the four countries in both scenarios (USA $\alpha_{1}=0.83, \alpha_{2}=0.87$; Mexico $\alpha_{1}=.80, \alpha_{2}=.89$; Peru $\alpha_{1}=0.73, \alpha_{2}=0.79$; Turkey $\alpha_{1}=0.83, \alpha_{2}=0.85$ ).

When comparing motivation before and after, students' motivation from Mexico $t_{(323)}=4.57, p<.001$, Peru, $t_{(284)}=14.27, p<.001$, and the USA $t_{(239)}=13.14, p<.001$, decreased after the transition to online learning, while Turkish students' motivation did not change significantly $\left(t_{(125)}=1.37, p>.05\right)$. We also examined the relation between students' motivation after the transition and their cognitive engagement. Students showed a positive significant correlation, being moderate in the USA, $r_{(225)}=.35$ and weak in Peru, $r_{(283)}=.28$, both at the $p<.001$ level. Mexico showed a weak positive correlation, $r_{(225)}=.16$ at the $p<.05$ level, and Turkey did not show a significant correlation between motivation after transition and cognitive engagement. This means that in the USA, Peru, and Mexico, the lower the students' motivation during online learning, the worse their cognitive engagement.

\subsection{Perceived behavioral control}

\subsubsection{Use of technology}

Regarding the use of technology, we asked students how frequently they used it before and after the transition to online learning. The use of technology before refers to students' previous experiences with technology that facilitate the ease of use (Abdullah and Ward 2016; Kemp et al. 2019; Venkatesh et al. 2003). The questions were the same for before and after the transition to online learning. We asked students, "For educational purposes, how often did you use: an online educational platform such as Canvas or Blackboard; communication tools such as Zoom or Teams, social media such as LinkedIn, Facebook, etc.; asynchronous videos assigned or typed by instructors; and synchronous class sessions?"

A one-way ANOVA and post hoc Tukey HSD analysis showed statistically significant differences in the use of technology before the transition among the four countries $(F=85.72, p<.001)$. The USA students had more experience with technology, followed by Mexico, Turkey, and lastly Peru.

We compared the use of technology before and after the stay-at-home order, and all the participants significantly increased their use of technology during the stay-at-home order $\left(\right.$ USA $t_{(238)}=19.02, p<.001$; Mexico $t_{(323)}=41.06, p<.001$; Peru $t_{(289)}=33.74$, $p<.001$; and Turkey $\left.t_{(125)}=21.85, p<.001\right)$. The sudden transition to emergency online learning forced students from the four countries to become more aware of technological tools than they previously were.

In the USA there is also a weak correlation between previous use of technology and preference for online learning $\left(r_{(242)}=.20, p<.05\right)$. This correlation was not significant 
for Mexico, Peru, or Turkey. US Students who preferred online learning had more experience with technology.

Furthermore, we found a significant positive weak correlation between previous use of technology (ease of use) and self-efficacy in the USA, $r_{(236)}=.15, p<.05$; Mexico, $r_{(323)}=.17, p<.05$; Peru $r_{(283)}=.15, p<.05$; and Turkey $r_{(125)}=.28, p<.05$. Data shows that the more experience students have with technology, the higher their perception of their own capabilities, in the four countries.

\subsubsection{Self-efficacy}

Self-efficacy refers to the students' judgment of their capabilities (Bandura 1977, 1986; Guerrero 2019). Students were asked how their following abilities have changed since the stay-at-home order: ability to complete assignments on time, ability to be successful in classes, ability to discuss topics with classmates and/or professors, and time management skills. The Cronbach's alpha analysis shows a good internal consistency in the four countries (USA $\alpha=.86$, Mexico $\alpha=.83$, Peru $\alpha=.79$, Turkey $\alpha=0.80$ ).

A one-way ANOVA analysis and post hoc comparisons using the Tukey HSD test indicated that students from Peru, Mexico, and Turkey showed a similar perception of self-efficacy (Table 2). Only students from the USA showed a statistically significant difference as compared to the other three countries. Even though the US students had more experience with technology, and there was a positive weak correlation between use of technology before transition and self-efficacy $\left(r_{(236)}=.15, p<.05\right)$, they showed the lowest mean in self-efficacy.

\subsubsection{Accessibility}

Accessibility refers to the degree to which a student perceives that access to educational technology is present (Kemp et al. 2019; Pham and Tran 2020). For this factor, we asked how often students have access to a reliable digital device (computer, tablet, or mobile device), a reliable internet service, communication software such as Skype, Zoom, or Teams, and if they have access to solve technical issues. Using the Cronbach's alpha test, responses showed an acceptable internal consistency in the USA $(\alpha=.77)$, Mexico $(\alpha=.72)$, and Turkey $(\alpha=.80)$, but not in Peru $(\alpha=.61)$.

A one-way ANOVA analysis and post hoc comparison of means (Tukey HSD) showed a significant difference where Mexican participants have more accessibility than students from the USA, Turkey, and Peru. The USA, Peru, and Turkey had similar means for accessibility.

\subsection{Cognitive engagement}

Cognitive engagement refers to the focus, attention, and absorption of the learner (Kemp et al. 2019; Saadé and Bahli 2005). Students were asked to report changes in their academic performance compared to how they were before the COVID-19 stay-athome order. We listed six categories: grades, knowledge/learning (related to school), concentration, level of engagement, class attendance, and interest and enthusiasm. We calculated Cronbach's alpha, which yielded a positive internal consistency in all four countries (USA $\alpha=.92$, Mexico $\alpha=.87$, Peru $\alpha=.88$, Turkey $\alpha=0.88$ ). 
There was a statistically significant difference between the countries when compared to a one-way ANOVA test. Post hoc comparison using the Tukey HSD test indicated that US students had a statistically significant lower cognitive engagement than students from Mexico, Peru, and Turkey.

Cognitive engagement is usually lower in the online environment than in face-toface classes. It is important to keep students engaged to have positive learning outcomes (Panigrahi et al. 2018). This research presents a model with the factors that may predict the use of online learning in the future based on the students' experience during emergency online learning.

Even though we followed Kemp et al.'s (2019) taxonomy with the most common factors to predict the use and acceptance of technology, we included only factors that may influence the students' cognitive engagement while using online learning in the future. For example, for attitude, we did not include face-to-face preference, only preference for online learning. For affect, we did not include emotional states because we assumed that they may not be completely reliable due to the pandemic; however, we included satisfaction with courses. We also did not include motivation after the stay-athome order because we assumed that motivation before would be the regular motivation of each student for pursuing studies. The model and its results are as follows (Fig. 2).

A linear model showed statistically significant differences between factors among the four countries. In the USA $\left(r^{2}=0.47, F=29.35, p<.001\right)$, this model explains $47 \%$ of the variability for cognitive engagement but only self-efficacy $(\beta=.67, p<.001)$ and preference for online learning $(\beta=.67, p<.05)$ showed significance towards cognitive engagement. This indicates that attitude and self-efficacy are relevant factors for predicting cognitive engagement among students in the USA while using online learning.

Regarding Mexico $\left(r^{2}=.34, F=27.76, p<.001\right)$, the multivariate model explained the $34 \%$ of variability. There were four significant factors that predict cognitive engagement among Mexican students, self-efficacy $(\beta=.454, p<.001)$, preference for online learning $(\beta=.115, p<.05)$, motivation to pursue studies before the transition

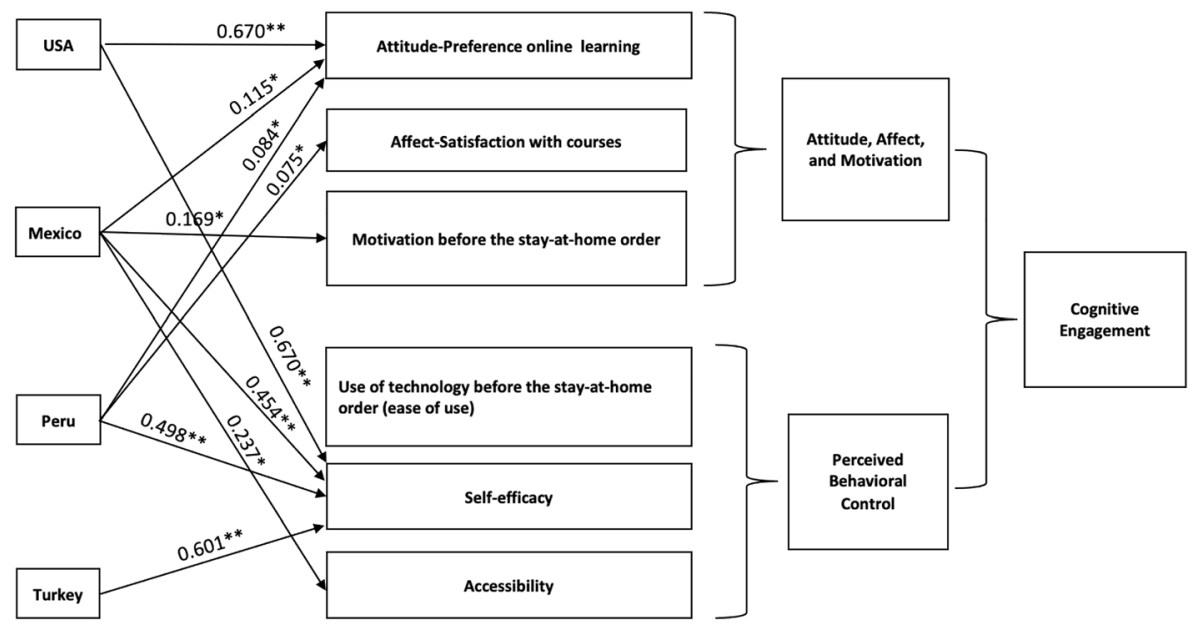

Fig. 2 Final model predicting cognitive engagement. $* p=0.05$, $* * p=0.01$ 
( $\beta=.169, p<.05)$, and accessibility $(\beta=.237, \mathrm{p}<.05)$. For Peru, the model explains $61 \%$ of the variability $\left(r^{2}=.59, F=61.34, p<.001\right)$. The factors that were statistically significant were self-efficacy $(\beta=.498, p<.001)$, preference for online learning $(\beta=.169, p<.05)$, and satisfaction with courses $(\beta=.169, p<.05)$. Finally, for Turkey $\left(r^{2}=.491, F=20.91, p<.001\right)$, the model explains $49 \%$ of the variability and only selfefficacy ( $\beta=.601, p<.001$ ) was significant enough to predict cognitive engagement.

Self-efficacy is the only factor that predicts cognitive engagement in online learning for the four countries. However, each country shows different significant factors that predict cognitive engagement among students.

\section{Discussion}

The COVID-19 pandemic forced higher education institutions to transition quickly to online learning in many countries (Affouneh et al. 2020; Aguilera-Hermida et al 2020; Almaiah et al. 2020; Gürler et al. 2020). However, not all countries had the same conditions, and students did not have the same resources to perform appropriately in novel circumstances, such as the online educational environment (Jung 2014; Pedró 2020). Even though emergency online learning is not completely online learning, the lack of physical interaction and the increase of activities through the computer require better time management and self-regulating skills than face-to-face classes (Ramírez and Rodríguez 2020).

Emergency online learning is not over; in many countries, the pandemic is not under control. The more that higher education institutions understand the factors affecting the use of emergency online learning, the easier it will be to continue offering online classes to students (due to an emergency or not). This study did not explore factors related to instruction or learning systems because during the pandemic, professors who were not familiar with online teaching did not have enough time to learn and/or develop effective online pedagogical approaches. Many professors had a low level of comfort while transitioning to online learning (Birch and Lewis 2020; Huang et al. 2020; Tang 2020).

After this transition, students and professors will be more familiar with the online environment. They can be trained to use OERs and this will increase the likelihood of their use in the future (Racero et al. 2020). The pandemic will be over, but the use of OERs should continue, as they are useful tools that can improve the learning process online, hybrid, or face-to-face. Educators can use their creativity and OERs to personalize learning, make the content more relevant, or adapt it to local context or specific student needs (Kadada and Tshabalala 2020; Ruipérez-Valiente et al. 2020; Van Allen and Katz 2020).

The use of OERs, especially those that utilize microlearning, can be a collaborative strategy where learners and educators can contribute to the co-construction of knowledge. Not only professors can incorporate OERs; students can also find and suggest learning materials (Huang et al. 2020,). The microlearning units have to be adapted to the learner needs, the type of content (chemistry, math, psychology, etc.), and the level of difficulty of the course (Birch and Lewis 2020).

This exploratory research analyzed the factors that affected the students' use of emergency online learning due to COVID-19 in four countries: Mexico, Peru, Turkey, 
and the United States of America (USA), and proposed a model for predicting cognitive engagement in online learning settings.

\subsection{Predicting cognitive engagement}

The predictive model showed that each country has different factors that act as moderators for cognitive engagement. Specific cultural differences affect the strength of some relationships within the acceptance models (Tarhini et al. 2017). Peru and Mexico had more factors that predicted cognitive engagement. Moreover, Peru and Mexico were the only countries that had motivation (Mexico) and affect (Peru) as predictors. This is likely related to cultural values; both countries are in Latin America and share Latin culture.

Attitude, affect, and motivation are factors related to internal focus and feelings, while perceived behavioral control is more closely linked to the learning context. Mexico, Peru, and the USA showed at least one factor related to perceived behavioral control, and one related to attitude, affect, and motivation. On the contrary, Turkey showed only one factor of perceived behavioral control that predicts cognitive engagement, but none related to attitude, affect, and motivation. Future research is necessary to analyze the affective elements impacting cognitive engagement in Turkey.

Cultural context can lead students to common approaches and direction, but also can offer new and rich experiences that create unique circumstances and constant change. These complexities shape students' perceptions of online learning (Jung 2014). Students from each country not only learned content but also had to adapt to the particular online learning experience that they received.

The environment is interconnected with the beliefs and knowledge of the participants, and thus influences the students' learning processes (Bower 2019). Consequently, it is important to use critical, rather than deterministic, approaches while providing online learning and deliberately framing the use of technology within the context of each country.

\subsection{Attitude, affect, and motivation impacted students' acceptance}

As findings showed, students from Mexico, Peru, Turkey, and the USA struggled with the transition to online learning. Their attitude towards the delivery method significantly marked their cognitive engagement. Those students who preferred in-person classes struggled more with emergency online learning and had lower cognitive engagement than those who had a positive attitude towards online learning. Our findings support that a positive attitude towards technology contributes to an improvement in self-regulated skills, and positively impacts learning (Albelbisi and Yasop 2019).

Even though online learning has increased in the last few decades and has shown similar learning outcomes than in-person teaching (Allen and Seaman 2015), there is still a preference for the face-to-face teaching method (Bali and Liu 2018; Panigrahi et al. 2018). Additionally, there is an assumption that online learning does not offer the same quality as face-to-face classes (Pedró 2020). Emergency online learning is not identical to online learning, however, preference for online learning is a predictor of cognitive engagement in Mexico, Peru, and the USA. Consequently, higher education institutions have to actively work on eliminating stereotypes surrounding online 
learning, and promote a positive attitude, so students can have a better experience when attending face-to-face classes is no longer an option.

Furthermore, the level of enjoyment (satisfaction) is a significant predictor of outcomes related to technology use and acceptance (Abdullah and Ward 2016; Saadé and Bahli 2005; Venkatesh et al. 2012). Students' satisfaction with online courses is a key component for successful experiences. Students who are satisfied with their courses tend to have higher grades. This is the case for Peruvian students, whose satisfaction was a predictor of cognitive engagement, but not for students from the USA, Mexico, or Turkey.

Students from the four countries experienced an increase in negative emotions such as anxiety and worry during the pandemic. Our findings are consistent with previous literature (Cao et al. 2020; Pedró 2020). Negative emotions affect cognitive processes such as attention, memory, problem solving, and therefore, learning outcomes (Engelmann and Bannert 2019). Lower levels of anxiety are related to better learning outcomes when students engage in online learning (Heckel and Ringeisen 2019). In Mexico, Peru, Turkey, and the USA, negative emotions negatively affected the students' cognitive engagement. These negative emotions may be related to the circumstances students were facing during the pandemic.

It is important to emphasize that motivation may or may not be a predictor of cognitive engagement. Our results partially confirm previous literature stating that motivation has a significant effect on the use of technology and leads to cognitive engagement (Maldonado et al. 2009), but it varies depending on the country. Motivation may predict cognitive engagement in Mexican students while using online learning, but not for students from Peru, Turkey, or the USA.

\subsection{Perceived behavioral control: Use of technology, self-efficacy, and accessibility}

After the transition to online learning, students from Mexico, Peru, Turkey, and the USA used more educational online tools than before. Previous computer-related experience (also called ease of use) has been considered a strong determinant for the use and acceptance of online learning. The more experience users have, the easier the use of technology will be (Abdullah and Ward 2016; Davis 1989; Maldonado et al. 2009; Thongsri et al. 2018). This may help them to have better experiences in hybrid and online courses in the future.

Venkatesh et al. (2012) stated that experience, per se, was not a relevant moderator for the use of technology. Findings from this study showed similar outcomes. Only in the USA, students who preferred online learning had more experience with the use of technology, but this relationship is not observed in any other country. Moreover, the use of technology was not a moderator for cognitive engagement in any of the four countries neither before, nor after the pandemic Even though the use of online learning before COVID-19 differed from country to country (Huang et al. 2020; Lloyd 2020), our findings showed that the use of technology before the transition did not predict cognitive engagement while using online learning.

Across the four countries, self-efficacy was the most significant factor for predicting cognitive engagement. This study supports previous literature about the positive impact that self-efficacy has on learning outcomes and the use of educational technologies (Abdullah and Ward 2016; Davis 1989; Heckel and Ringeisen 2019; Panigrahi et al. 2018). Almaiah et al. (2020) found that self-efficacy is one of the core elements for the 
adoption of e-learning systems during the pandemic. The student's belief in their own ability to successfully perform expected academic behaviors affects, and is directly related to, academic performance. Students who are confident in their skills to learn are more motivated to engage in the learning process and have higher academic performances in both traditional and online learning environments (Alghamdi et al. 2020; Wang et al. 2013). Self-efficacy was a powerful predictor of cognitive engagement in Mexico, Peru, Turkey, and the USA.

This research shows that accessibility was a significant predictor of cognitive engagement in Mexico, but not in Peru, Turkey, or the USA. Moreover, students from Mexico have more accessibility than students from any other country. This seems contradictory to the literature that states that only $45 \%$ of Mexicans have access to a computer and 53\% have access to the internet at home (Lloyd 2020) and 52\% of homes in Latin America have access to reliable technology and broadband connectivity (Pedró 2020). There is no homogeneity in the use of the internet among countries (GomezGalan et al. 2020).

These results may be explained by the fact that the Mexican students who participated in the study were from a private school and had a high socioeconomic status. In Mexico, like in other countries, students from private schools have greater access to online classes than those from public schools. Furthermore, professors from private schools tend to have more experience and access to technology, and students can use those resources, too (Lloyd 2020). Another important factor is that the Mexican school provided internet and devices for those students who did not have it; whereas the participants in the USA, Peru, and Turkey were from a state university that did not provide internet or other technological resources to students who needed it.

\section{Limitations}

Besides the contributions mentioned above, the study has some limitations. Our study is limited by convenience sampling and lack of balanced participation, e.g., by gender or by geographical region. A further limitation is the use of self-report measures which are prone to socially desirable answers. Also, the cross-sectional design of this study cannot establish a cause-effect relationship between the stay-at-home measures and whether remote teaching and learning has affected their learning process. Any generalization to other populations should be made with caution.

During the transition to emergency online learning, many professors were not knowledgeable of instructional strategies for online learning. The transition was so sudden that universities and professors used what they could (e.g. Zoom, Google classroom, Microsoft Teams, Messenger, and WhatsApp). Many higher education institutions were not prepared with appropriate e-learning platforms and online educational resources. Also, the social conditions of the learning environment have been highly affected by the lockdown restrictions due to the pandemic (Figallo et al. 2020; Gürler et al. 2020; Lloyd 2020). Therefore, we did not include factors related to the social environment, usefulness and visibility of technology, and instructional attributes. More research is necessary to understand how professors are integrating instructional strategies that promote cognitive engagement such as microlearning (Diaz-Redondo 
et al. 2021) and open educational resources that are available around the world (Huang et al. 2020).

\section{Conclusions}

This study shows that it is not possible to apply a single approach for all cases regarding emergency online learning. It is a challenge to provide high-quality education to all students while continuing with this contingency. The students' use and acceptance of online learning in an emergency context, like the COVID-19 pandemic, differs in Mexico, Peru, Turkey, and the USA. The technological infrastructure and socioeconomic context of each country play an important role, and so too do the particular conditions that each student faces. As Bozkurt and Sharma (2020) state, the privileged may have more benefits that are independent of the country in which they reside. The digital divide is a threat, and the lack of resources and/or digital competencies will result in unavailable educational opportunities (Pedró 2020).

Moreover, based on the model, it is not relevant whether or not students knew technology before the transition to online learning. Knowledge of technology was not a predicting factor for cognitive engagement in any of the countries. This could be interpreted as students learning technology and using it, but this is not a factor that affects learning outcomes. In the four countries, the use of technology increased significatively after the transition to online learning (Table 2), but that does not necessarily mean that students are going to be cognitively engaged. These results have to be considered when professors and higher education institutions add new technologies or software to the classroom. Students may learn and use new technologies, but that does not mean that they will have better academic outcomes.

The pandemic forced faculty members and students to use technology in the classroom. More higher education institutions are incorporating online learning as part of their educational programs. Therefore, higher education institutions should provide training to professors to ensure that better technological systems and instructional strategies are incorporated (Ruipérez-Valiente et al. 2020). Professors should be able to select OERs based on quality of the content, interactivity, ease of use, and licensing. Also, they should be able to use microlearning and adapt it to their particular needs. Professors can use national and international repositories where resources can be used without specific technical skills (Huang et al. 2020).

Furthermore, OERs can contribute to social justice and help to lessen disparities (Tang 2020; Van Allen and Katz 2020). Students from developing countries and/or rural areas can have access to education as soon as they have access to a smartphone (Kadada and Tshabalala 2020). Administrators and faculty members have to analyze the particular circumstances of their students and become not only supportive educators but also be encouraging of their students. No matter the subject, the emergency online learning transition has been a difficult experience for many students around the globe.

The predictive model presented can help educators to identify what factors are most relevant for each country and develop specific supporting programs so students can reach the highest possible cognitive engagement during online learning in emergency contexts. 
Self-efficacy was the most significant predictor of cognitive engagement within the four countries. Therefore, faculty members should help students to identify their resources and improve their confidence. By observing their previous academic achievements, students will discern which responses are better, and increase their efficacy expectations. Once established, enhanced self-efficacy tends to generalize to other situations (Bandura 1977, 1986). Students must perceive themselves as capable of handling school during these challenging times.

Future research can focus on analyzing how many students started taking more online courses due to increased familiarity with the online environment. Additionally, it would be important to observe the drop-out rates in higher education and the relationship with the student's experience during emergency online learning due to COVID-19. Finally, another important line of research is to develop specific strategies and/or interventions that can increase students' sense of academic self-efficacy, especially when this is a factor that predicts cognitive engagement in students from different countries.

Author's contribution Conceptualization: Aguilera-Hermida, A.P., Quiroga-Garza, A., Gómez-Mendoza, S.; Methodology: Aguilera-Hermida, A.P., Quiroga-Garza, A., Gómez-Mendoza, S.; Del Rio-Villanueva, C.A., Avolio-Alecchi B. E., Avci, D.; Formal analysis: Aguilera-Hermida, A.P.; Writing - original draft preparation: Aguilera Hermida, A.P.; Writing - review and editing: Aguilera-Hermida, A.P., Quiroga-Garza, A., Gómez-Mendoza, S.; DelRio-Villanueva, C.A., Avolio-Alecchi B. E.

Data availability Contact the corresponding author.

Code availability Not applicable.

\section{Declarations}

Conflicts of interest/competing interests The authors declare they have no financial interests.

\section{References}

Abdullah, F., \& Ward, R. (2016). Developing a general extended technology acceptance model for E-learning (GETAMEL) by analysing commonly used external factors. Computers in Human Behavior, 56, 238256. https://doi.org/10.1016/j.chb.2015.11.036.

Affouneh, S., Salha, S., \& Khlaif, Z. N. (2020). Designing quality e-learning environments for emergency remote teaching in coronavirus crisis. Interdisciplinary Journal of Virtual Learning in Medical Sciences, 11(2), 135-137. https://doi.org/10.30476/ijvlms.2020.86120.1033.

Aguilera-Hermida, A. P. (2020). College students' use and acceptance of emergency online learning due to Covid-19. International Journal of Educational Research Open, 1. https://doi.org/10.1016/j.ijedro.2020. 100011.

Albelbisi, N. A., \& Yusop, F. D. (2019). Factors influencing learners' self-regulated learning skills in a massive open online course (MOOC) environment. Turkish Online Journal of Distance Education, 20(3), 1-16. https://doi.org/10.17718/tojde.598191.

Alghamdi, A., Karpinski, A. C., Lepp, A., \& Barkley, J. (2020). Online and face-to-face classroom multitasking and academic performance: Moderated mediation with self-efficacy for self-regulated learning and gender. Computers in Human Behavior, 102, 214-222. https://doi.org/10.1016/j.chb.2019.08.018.

Ali, W. (2020). Online and remote learning in higher education institutes: A necessity in light of COVID-19 pandemic. Higher Education, 10(3), 16. https://doi.org/10.5539/hes.v10n3p16.

Allen, I. E., \& Seaman, J. (2015). Grade level: Tracking online education in the United States. Babson College: Babson Survey Research Group. 
Almaiah, M. A., Al-Khasawneh, A., \& Althunibat, A. (2020). Exploring the critical challenges and factors influencing the E-learning system usage during COVID-19 pandemic. Education and Information Technologies, 25, 5261-5280. https://doi.org/10.1007/s10639-020-10219-y.

Bali, S., \& Liu, M. C. (2018). Students' perceptions toward online learning and face-to-face learning courses. Journal of Physics: Conference Series, 1108, 12094. https://doi.org/10.1088/1742-6596/1108/1/012094.

Bandura, A. (1977). Self-efficacy: toward a unifying theory of behavioral change. Psychological Review, 84(2), 191-215.

Bandura, A. (1986). The explanatory and predictive scope of self-efficacy theory. Journal of Social and Clinical Psychology, 4(3), 359-373. https://doi.org/10.1521/jscp.1986.4.3.359.

Bandura, A., \& Adams, N. E. (1977). Analysis of self-efficacy theory of behavioral change. Cognitive Therapy and Research, 1(4), 287-310. https://doi.org/10.1007/BF01663995.

Birch, R., \& Lewis, K. (2020). Building partnerships to support teachers with distance learning during the covid-19 pandemic. Issues in Teacher Education, 29(1), 149-157.

Bosco, M. D., \& Barrón, H. (2008). La educación a distancia en México: narrativa de una historia silenciosa. Universidad Nacional Autónoma de México.

Bower, M. (2019). Technology-mediated learning theory. British Journal Education Technology, 50, 10351048. https://doi.org/10.1111/bjet.12771.

Bozkurt, A., \& Sharma, R. C. (2020). Emergency remote teaching in a time of global crisis due to coronavirus pandemic. Asian Journal of Distance Education, 15(1), i-vi. https://doi.org/10.5281/zenodo.3778083.

Cao, W., Fang, Z., Hou, G., Han, M., Xu, X., Dong, J., \& Zheng, J. (2020). The psychological impact of the COVID-19 epidemic on college students in China. Psychiatry Research, 112934, 112934. https://doi.org/ 10.1016/j.psychres.2020.112934.

Crawford, J., Butler-Henderson, K., Rudolph, J., \& Glowatz, M. (2020). COVID-19: 20 Countries' higher education intra-period digital pedagogy responses. Journal of Applied Teaching and Learning (JALT), 3(1). https://doi.org/10.37074/jalt.2020.3.1.7.

Cueva, M. A. L., \& Terrones, S. A. C. (2020). Repercusiones de las clases virtuales en los estudiantes universitarios en el contexto de la cuarentena por covid-19: El caso de la PUCP. Propósitos y Representaciones, 8(SPE3), 588. https://doi.org/10.20511/pyr2020.v8nSPE3.588.

Daniel, S. J. (2020). Education and the COVID-19 pandemic. Prospects, 1-6.

Davis, F. (1989). Perceived usefulness, perceived ease of use, and user acceptance of information technology. MIS Quarterly, 13(3), 319-340. https://doi.org/10.2307/249008.

Díaz Redondo, R. P., Caeiro Rodríguez, M., López Escobar, J. J., \& Fernández Vilas, A. (2021). Integrating micro-learning content in traditional e-learning platforms. Multimedia Tools and Applications, 80(2), 3121-3151. https://doi.org/10.1007/s11042-020-09523-z.

Emrich, V., Senior, E., Ford, G., Hicks, L., \& Riesett, B. (2019). Maryland's journey with OER. Knowledge Quest, 48(2), 36-41.

Engelmann, P., \& Bannert, M. (2019). Fostering students' emotion regulation during learning: Design and effects of a computer-based video training. The International Journal of Emotional Education, 11(2), 316.

Figallo, F., González, M. T., \& Diestra, V. (2020). Perú: Educación superior en el contexto de la pandemia por el COVID-19. Revista de Educación Superior en América Latina, 8.

Gomez-Galan, J., Vergara, D., Ordonez-Olmedo, E., \& Veytia-Bucheli, M. G. (2020). Time of use and patterns of internet consumption in university students: A comparative study between spanish-speaking countries. Sustainability (Basel, Switzerland), 12(12), 5087. https://doi.org/10.3390/su12125087.

Gonzalez, T., de la Rubia, M., Hincz, K., Lopez, M. C., Subirats, L., Fort, S., \& Sacha, G. M. (2020, April 20). Influence of COVID-19 confinement in students' performance in higher education. https://doi.org/10. 35542/osf.io/9zuac.

Guerrero, F. N. T. (2019). Aceptación de los estudiantes universitarios en el uso de los sistemas e-learning Moodle desde la perspectiva del Modelo TAM.//acceptance of university students in the use of Moodle elearning systems from the perspective of the TAM model. Revista Ciencia UNEMI, 12(29), 63-76.

Gürler, C., Uslu, T., \& Daștan, İ. (2020). Evaluation of distance learning from student perspective in Covid-19 pandemic. Atatürk Üniversitesi Sosyal Bilimler Enstitüsü Dergisi, 24(4), 1895-1904.

Hall, T., Connolly, C., Grádaigh, S. Ó., Burden, K., Kearney, M., Schuck, S., ... Koenraad, T. (2020). Education in precarious times: A comparative study across six countries to identify design priorities for mobile learning in a pandemic. Information and Learning Sciences. http://hdl.handle.net/10453/141776. Accessed 23 July 2020.

Harasim, L. (2000). Shift happens: Online education as a new paradigm in learning. The Internet and Higher Education, 3(1-2), 41-61. https://doi.org/10.1016/S1096-7516(00)00032-4. 
Heckel, C., \& Ringeisen, T. (2019). Pride and anxiety in online learning environments: Achievement emotions as mediators between learners' characteristics and learning outcomes. Journal of Computer Assisted Learning, 35, 667-677. https://doi.org/10.1111/jcal.12367.

Hilton, J. (2020). Open educational resources, student efficacy, and user perceptions: A synthesis of research published between 2015 and 2018. Educational Technology Research and Development, 68(3), 853-876. https://doi.org/10.1007/s11423-019-09700-4.

Hodges, C., Moore, S., Lockee, B., Trust, T., \& Bond, A. (2020). The difference between emergency remote teaching and online learning. EDUCAUSE Review. Retrieved from: https:/er.educause.edu/articles/2020/ 3/the-difference-between-emergency-remote-teaching-and-online-learning. Accessed 24 July 2020.

Huang, R., Tlili, A., Chang, T. W., Zhang, X., Nascimbeni, F., \& Burgos, D. (2020). Disrupted classes, undisrupted learning during COVID-19 outbreak in China: Application of open educational practices and resources. Smart Learning Environments, 7(1). https://doi.org/10.1186/s40561-020-00125-8.

Jahnke, I., Lee, Y. M., Pham, M., He, H., \& Austin, L. (2020). Unpacking the inherent design principles of mobile microlearning. Technology, Knowledge and Learning, 25(3). Netherlands: Springer. https://doi. org/10.1007/s10758-019-09413-w.

Jung, I. (2014). Cultural influences on online learning. In I. Jung, \& C. Nirmalani (Eds.), Culture and online learning: Global perspectives and research (pp. 15-24). Stylus Publishing. https://doi.org/10.1080/ 08923647.2016.1164507, 30, 125, 127.

Jung, I., \& Lee, J. (2020). A cross-cultural approach to the adoption of open educational resources in higher education. British Journal of Educational Technology, 51(1), 263-280. https://doi.org/10.1111/bjet.12820.

Kadada, C., \& Tshabalala, T. (2020). Students' attitudes to open educational resources (OERs). International Journal of Social Sciences and Educational Studies, 7(3), 9-19. https://doi.org/10.23918/ijsses.v7i3p9.

Kemp, A., Palmer, E., \& Strelan, P. (2019). A taxonomy of factors affecting attitudes towards educational technologies for use with technology acceptance models. British Journal Education Technology, 50, 2394-2413. https://doi.org/10.1111/bjet.12833.

Lloyd, M. W. (2020). Desigualdades educativas y la brecha digital en tiempos de COVID-19. En J. Girón (Ed.), Educación y pandemia: una visión académica. ISSUE, Universidad Nacional Autónoma de México.

Maldonado, U. P. T., Khan, G. F., Moon, J., \& Rho, J. J. (2009, November). E-learning motivation, students' acceptance/use of educational portal in developing countries: A case study of Peru. In 2009 Fourth International Conference on Computer Sciences and Convergence Information Technology, 1431-1441. https://doi.org/10.1109/ICCIT.2009.77.

Martinho, D. S., Santos, E. M., Miguel, M. I., \& Cordeiro, D. S. (2018). Factors that influence the adoption of postgraduate online courses. International Journal of Emerging Technologies in Learning (iJET), 13(12), 123-141. https://doi.org/10.3991/ijet.v13i12.8864.

Murphy. (2020). COVID-19 and emergency eLearning: Consequences of the securitization of higher education for post-pandemic pedagogy. Contemporary Security Policy, 41, 492-505. https://doi.org/10.1080/ 13523260.2020.1761749.

Panigrahi, R., Srivastava, P. R., \& Sharma, D. (2018). Online learning: Adoption, continuance, and learning outcome-A review of literature. International Journal of Information Management, 43, 1-14.

Park, C., Kim, D. G., Cho, S., \& Han, H. J. (2019). Adoption of multimedia technology for learning and gender difference. Computers in Human Behavior, 92, 288-296. https://doi.org/10.1016/j.chb.2018.11.029.

Pedró, F. (2020). COVID-19 y educación superior en América Latina y el Caribe: Efectos, impactos y recomendaciones políticas. Análisis Carolina, 36.

Pham, Q. T., \& Tran, T. P. (2020). The acceptance of e-learning systems and the learning outcome of students at universities in Vietnam. Knowledge Management \& E-Learning, 12(1), 63-84. https://doi.org/10. 34105/j.kmel.2020.12.004.

Racero, F. J., Bueno, S., \& Gallego, M. D. (2020). Predicting students' behavioral intention to use open source software: A combined view of the technology acceptance model and self-determination theory. Applied Sciences (Switzerland), 10(8). https://doi.org/10.3390/APP10082711.

Ramírez, M. L., \& Rodríguez, S. A. (2020). Trayectorias escolares en la educación superior ante la pandemia_ continuar, interrumpir o desistir? En J. Girón (Ed.), Educación y pandemia: Una visión académica (pp. 103-109). ISSUE, Universidad Nacional Autónoma de México.

Ruipérez-Valiente, J. A., Martin, S., Reich, J., \& Castro, M. (2020). The unMOOCing process: Extending the impact of MOOC educational resources as OERs. Sustainability (Switzerland), 12(18), 1-17. https://doi. org/10.3390/SU12187346.

Saadé, R., \& Bahli, B. (2005). The impact of cognitive absorption on perceived usefulness and perceived ease of use in on-line learning: An extension of the technology acceptance model. Information \& Management, 42(2), 317-327. https://doi.org/10.1016/j.im.2003.12.013. 
Tang, H. (2020). Implementing open educational resources in digital education. Educational Technology Research and Development, 0123456789, 10-13. https://doi.org/10.1007/s11423-020-09879-x.

Tarhini, A., Hone, K., Liu, X., \& Tarhini, T. (2017). Examining the moderating effect of individual-level cultural values on users' acceptance of E-learning in developing countries: A structural equation modeling of an extended technology acceptance model. Interactive Learning Environments, 25(3), 306-328. https:// doi.org/10.1080/10494820.2015.1122635.

Thongsri, N., Shen, L., Bao, Y., \& Alharbi, I. M. (2018). Integrating UTAUT and UGT to explain behavioural intention to use M-learning. Journal of Systems and Information Technology, 20(3), 278-297. https://doi. org/10.1108/JSIT-11-2017-0107.

UNESCO (2020). Guidelines on the development of open educational resources policies. Scientific and Cultural Organization (UNESCO): United Nations. https://unesdoc.unesco.org/ark:/48223/ pf0000371129. Accessed 24 Jan 2020.

Van Allen, J., \& Katz, S. (2020). Teaching with OER during pandemics and beyond. Journal for Multicultural Education, 14(3-4), 209-218. https://doi.org/10.1108/JME-04-2020-0027.

Venkatesh, V., Morris, M. G., Davis, G. B., \& Davis, F. D. (2003). User acceptance of information technology: Toward a unified view. MIS Quarterly, 27(3), 425-478. https://doi.org/10.2307/30036540.

Venkatesh, V., Thong, J., \& Xu, X. (2012). Consumer acceptance and use of information technology: Extending the unified theory of acceptance and use of technology. MIS Quarterly, 36(1), 157-178. https://oi.org/10.2307/41410412.

Wang, C. H., Shannon, D. M., \& Ross, M. E. (2013). Students' characteristics, self-regulated learning, technology self-efficacy, and course outcomes in online learning. Distance Education, 34(3), 302-323. https://doi.org/10.1080/01587919.2013.835779.

World Health Organization. (2020). Coronavirus disease (COVID-19). Situation report - 185. https://www. who.int/docs/default-source/coronaviruse/situation-reports/20200723-covid-19-sitrep-185.pdf?sfvrsn= 9395b7bf 2. Accessed 23 July 2020.

Yakubu, M. N., \& Dasuki, S. I. (2019). Factors affecting the adoption of e-learning technologies among higher education students in Nigeria: A structural equation modeling approach. Information Development, 35(3), 492-502. https://doi.org/10.1177/0266666918765907.

Publisher's note Springer Nature remains neutral with regard to jurisdictional claims in published maps and institutional affiliations.

\title{
Affiliations
}

\section{A. Patricia Aguilera-Hermida ${ }^{1}$ - Angélica Quiroga-Garza ${ }^{2}$. Sanjuana Gómez-Mendoza ${ }^{2}$ - Carmen Amalia Del Río Villanueva ${ }^{3}$. Beatrice Avolio Alecchi ${ }^{3}$. Dilek Avci ${ }^{4}$}

\author{
A. Patricia Aguilera-Hermida \\ aua240@psu.edu; patricia_aguilera@hotmail.com
}

1 School of Behavioral Sciences and Education, The Pennsylvania State University, 777 West Harrisburg Pike, W314 Olmsted Building, Middletown, PA 17057, USA

2 Psychology Department, Universidad de Monterrey, Ave. Ignacio Morones Prieto 4500 Pte., 66238 San Pedro, Garza García, N.L., Mexico

3 CENTRUM Católica Graduate Business School, Pontificia Universidad Católica del Perú, Avenida Universitaria 1801, San Miguel, Lima, Peru

4 Department of Psychological Counseling and Guidance \& Psychological Center, Hacettepe University, Ankara, Turkey 